\title{
Otitis, rhinitis, and atopy in relation to domestic endotoxin and $\beta$-glucan exposure among children in Singapore
}

\author{
Lynne Lim Hsueh Yee · Amilia Wee Li Yan • \\ Ragnar Rylander
}

Received: 13 August 2009/ Accepted: 16 February 2010/Published online: 2 April 2010

(C) The Japanese Society for Hygiene 2010

\begin{abstract}
Background Exposure to microbial cell wall agents (MCWAs) has been related to the risk for atopy, otitis, and rhinitis.

Objectives To relate domestic exposure to two important MCWAs- $\beta$-glucan and endotoxin-to the risk for otitis, rhinitis, atopy, and allergy in a sample of children from Singapore.

Methods Subjects $(n=98)$ were recruited from July 2006 to December 2008. Blood samples were taken to determine nonspecific IgE and skin prick tests were performed. Dust samples were collected from the bedrooms of the subjects and analyzed for the content of $\beta$-glucan and endotoxin, using the Limulus method.

Results Levels of IgE were significantly higher among children with rhinitis, and these children also had a larger proportion of atopics. There were no differences in $\beta$-glucan values between children with otitis, children with rhinitis, and controls. Endotoxin levels were lower in the homes of children with otitis, with a tendency for the levels to be lower in those with rhinitis. Among children with a high level of $\beta$-glucan, there was a higher proportion of those with high $\mathrm{IgE}$ values and atopy.

Conclusions The results suggest that a low level of endotoxin is a risk factor for otitis and that a high level of $\beta$-glucan is a risk factor for atopic sensitisation. Reactions
\end{abstract}

L. L. H. Yee $(\bowtie) \cdot$ A. W. L. Yan

Department of Otolaryngology,

National University of Singapore, National University Hospital,

5 Lower Kent Ridge Road, Singapore 119074, Singapore

e-mail: entwlya@nus.edu.sg

R. Rylander

BioFact Environmental Health Research Center, Lerum, Sweden

e-mail: envhealth@biofact.se to domestic indoor exposure are determined by several indoor agents and their relative exposure levels.

Keywords Otitis - Rhinitis - Endotoxin $\cdot \beta$-Glucan · Atopy

\section{Introduction}

The early childhood disease panorama is dominated by respiratory infections, rhinitis, and otitis. Ever since Strachan published the theory on the hygiene hypothesis [1], it has become more and more apparent that exposure to microbial cell wall agents (MCWAs) plays an important role in the pathogenesis of these diseases. There are numerous studies that demonstrate an influence of bacterial endotoxin (lipopolysaccharide; LPS) on atopy, allergic skin disease, and asthma [2-6]. Endotoxin as such causes an inflammatory response in the airways and has been shown to increase the frequency of wheeze and airways irritation among children as well as adults. Several studies demonstrate that exposure to environments with a higher level of endotoxin in infancy will decrease the risk of atopy, asthma, and atopic dermatitis [3, 7, 8].

Apart from endotoxin, the home environment comprises exposure to other MCWAs, particularly $\beta$-glucan and chitin from mould cell walls. $\beta$-Glucan in small doses has been shown to depress immune function and sensitise the host to a simultaneous exposure to endotoxin [9, 10]. A relationship between fungi and allergic rhinitis has been reported [11, 12], as well as a relationship between fungal exposure and otitis [13]. The medical outcome of domestic exposure is thus determined by the combined exposure to different agents, and the prevailing disease will depend on the relative proportions of the different agents present. 
To further explore the relationships between domestic exposure to MCWAs and common diseases in small children, a study was undertaken where home levels of endotoxin and $\beta$-glucan were related to the risk for rhinitis, otitis, allergy, and atopic sensitisation among children in Singapore.

\section{Materials and methods}

\section{Subjects}

Subjects for the study $(n=98)$ were voluntarily recruited consecutively from regular patients at the Otolaryngology Outpatient Clinic at the National University Hospital in Singapore. Based upon an examination by a clinical practitioner, we recruited children with rhinitis (congestion, sneezing, itching, and postnasal discharge), children with otitis media (recurrent disease requiring myringotomy or with flat tympanograms on at least two occasions lasting 3 months or longer after antibiotic treatment), and children without these diseases as controls.

A questionnaire about the subjects' living habits and conditions was administered to the parents. Questions were asked on the presence of allergy to food, animals, and medication. The results were expressed as "allergy yes/no" for any type of allergy reported. Furthermore, consent was taken for the collection of dust samples. The duration of the stay in the flat/house was an average of 5.3 years with no difference between children with disease and controls. The study was approved by the Institutional Review Board at the University of Singapore and adhered to the standards of the Helsinki Declaration.

\section{Clinical examinations}

The subjects underwent regular standard diagnostic procedures for otitis and rhinitis. Three milliliters of blood was taken in ethylenediaminetetraacetate (EDTA) tubes for the determination of $\operatorname{IgE}$. Due to the young age group of the subjects, blood was only taken from subjects undergoing surgery for tonsillitis or adeno hypertrophy.

Atopy was determined with a skin prick test using a battery of 15 common allergens after confirming that antihistamine drugs were not consumed. A multiple skin test applicator (Multi-Test II; Lincoln Diagnostics, Decatur, IL, USA) was used to prick the skin. The distance between each needle was $2 \mathrm{~cm}$. One drop of extract was applied to the marked positions. Histamine hydrochloride was used as the positive control and phenolated glycerolsaline was used as the negative control. The extracts were left on the skin for $20 \mathrm{~min}$, after which the skin was swabbed with alcohol to remove the extracts. A pen was used to circle the wheals and a ruler was used to measure the diameter. A positive result was recorded when a $3 \times 3 \mathrm{~mm}$ wheal was present. Atopy was defined as a positive skin prick test to any allergen tested.

Determination of endotoxin and B-glucan

Floor dust from the bedrooms of the children was collected using a handheld vacuum cleaner (Pelican; Philips, Singapore). Coffee filters (Boncafe Filter Bags; Boncafe, Singapore) were fitted into the vacuum cleaner to collect dust samples. Parents were instructed not to vacuum-clean the floor for a day. A one-by-one meter surface area was vacuumed during $5 \mathrm{~min}$. The dust was weighed, suspended in $10 \mathrm{~mL}$ of LAL-reagent water, and shaken for $15 \mathrm{~min}$. One milliliter of the extract was withdrawn from the solution for endotoxin analysis. $\beta$-Glucan was extracted from the same sample by adding $1 \mathrm{~mL}$ of $3 \mathrm{~N} \mathrm{NaOH}$ to the suspension $(9 \mathrm{~mL})$. The sample was then shaken for $15 \mathrm{~min}$, after which $1 \mathrm{~mL}$ was withdrawn for the $\beta$-glucan analyses.

Serial dilutions were prepared of the two extracts using LAL-reagent water. The amount of endotoxin was determined using the Limulus Amebocyte Lysate assay (Pyrocrome; Cape Cod Incorporated, East Falmouth, MA, USA). The amount of $\beta$-glucan was determined using a glucanspecific version of the Limulus Amebocyte Lysate assay (Glucatell; Cape Cod Incorporated). For both endotoxin and $\beta$-glucan the kinetic procedure was used. The analyses were performed at Mycometer A/S in Copenhagen, Denmark. For technical reasons endotoxin was only determined in a limited number of samples $(n=55)$.

Statistical analysis

The amounts of endotoxin and $\beta$-glucan were compared for the groups with different diagnoses and for those with atopy/no atopy and allergy/no allergy. Statistical significance was assessed using the Mann-Whitney test and Fisher's exact test, with $P=0.05$ as the threshold for significance. There are minor differences in the numbers of children in different disease groups in the Tables as all tests could not be done on all children due to technical difficulties.

\section{Results}

The final cohort comprised 98 subjects (24 controls, 56 with rhinitis and 18 with otitis). The average age was 6.5 years (SD 3.2) with no difference between genders. Age and gender distributions were very similar in the different diagnostic groups. 
Table 1 Clinical findings among children with different diseases

\begin{tabular}{|c|c|c|c|c|c|c|c|}
\hline \multirow[t]{2}{*}{ Disease } & \multirow[t]{2}{*}{$n$} & \multicolumn{2}{|c|}{$\mathrm{IgE} \mathrm{mg} / \mathrm{L}$} & \multicolumn{2}{|c|}{ Atopy } & \multicolumn{2}{|c|}{ Allergy } \\
\hline & & $n$ & Mean (SE) & $n$ & $\%$ & $n$ & $\%$ \\
\hline Control & 24 & 21 & $123(43)$ & 12 & 50 & 10 & 50 \\
\hline Rhinitis & 56 & 50 & $311(56)^{*}$ & 47 & $94^{\#}$ & 36 & $70^{\infty}$ \\
\hline Otitis & 18 & 18 & 118 & 12 & 67 & 7 & 39 \\
\hline
\end{tabular}

* $P=0.016 ;{ }^{\#} P=0.003 ;{ }^{\circledR} P=0.06$

Housing characteristics

There was no relationship between the levels of $\beta$-glucan and endotoxin in the homes. The material was analyzed in relation to the presence of air conditioners in the homes of the children; there were no differences in $\beta$-glucan or endotoxin values. In homes with air conditioners, the average $\mathrm{IgE}$ values were higher (169 vs. $83 \mathrm{mg} / \mathrm{L}$ ), but the difference was not statistically significant.

\section{Clinical characteristics}

The clinical data for children with different diseases are reported in Table 1.

Among children with rhinitis, the levels of $\operatorname{IgE}$ and the proportion of atopics were higher than in the other groups ( $P=0.016$ Mann-Whitney and $P=0.003$ Fisher's exact test) and there was a tendency to a higher proportion of children with allergy $(P=0.06)$.

The amounts of endotoxin and $\beta$-glucan in relation to the different diseases are reported in Table 2 .

The endotoxin level was lower in the homes of children with otitis $(P=0.019)$, with a tendency for lower levels in the homes of children with rhinitis $(P=0.105)$.

The results from the skin prick testing demonstrated that 71 children $(74 \%)$ were atopic. Of those, $10(14 \%)$ were atopic to moulds. The levels of endotoxin and $\beta$-glucan in relation to atopy are reported in Table 3.

There was a slightly higher level of $\beta$-glucan in the homes of children with atopy, but the difference was not statistically significant. Among those with a $\beta$-glucan level above the first quartile $(12.0 \mathrm{ng} / \mathrm{mg})$, there was a significantly $(P=0.049)$ larger number of children with $\operatorname{IgE}$ values above 305 (3rd quartile) and a tendency to a higher proportion of atopic children (54 out of $71-76 \%$ as compared to 16 out of $24(67 \%)$ in the lower exposure group (not significant; NS).

Allergy was reported for 73 children (78\%). The levels of endotoxin, $\beta$-glucan, and $\operatorname{IgE}$ in relation to reported allergy are shown in Table 4.

There was a significantly lower level of endotoxin in the homes of children with allergy $(P=0.025)$. When the group with high levels of endotoxin ( 3 quartile, $>6.0 \mathrm{ng} / \mathrm{mg}$ ) in
Table 2 Amounts of $\beta$-glucan and endotoxin (ng/mg dust) in homes of children with different diseases

\begin{tabular}{lllllll}
\hline Disease & \multirow{2}{*}{$n$} & \multicolumn{2}{l}{$\beta$-Glucan } & & \multicolumn{2}{l}{ Endotoxin } \\
\cline { 3 - 4 } \cline { 7 - 7 } & & $n$ & Mean (SE) & & $n$ & Mean (SE) \\
\hline Control & 24 & 24 & $31.0(4.3)$ & & 10 & $9.3(2.5)$ \\
Rhinitis & 56 & 55 & $35.5(5.2)$ & & 31 & $5.0(1.1)^{\#}$ \\
Otitis & 18 & 18 & $35.4(5.6)$ & & $1.8(0.5)^{*}$ \\
\hline
\end{tabular}

* $P=0.019 ;{ }^{\#} P=0.105$

Table 3 Levels of $\beta$-glucan (ng/mg dust), endotoxin (ng/mg dust), and $\operatorname{IgE}(\mathrm{mg} / \mathrm{mL})$ in relation to atopy

\begin{tabular}{|c|c|c|c|c|c|c|c|}
\hline \multirow[t]{2}{*}{ Atopy } & \multirow[t]{2}{*}{$n$} & \multicolumn{2}{|c|}{$\beta$-Glucan } & \multicolumn{2}{|c|}{ Endotoxin } & \multicolumn{2}{|c|}{$\operatorname{IgE}$} \\
\hline & & $n$ & Mean (SE) & $n$ & Mean (SD) & $n$ & Mean (SE) \\
\hline No & 25 & 25 & $31.4(5.4)$ & 12 & 6.4 (1.9) & 23 & $22.5(5.3)$ \\
\hline Yes & 71 & 70 & $35.2(4.1)$ & 34 & $5.3(1.2)$ & 65 & $303(45.3)$ \\
\hline
\end{tabular}

Table 4 Levels of $\beta$-glucan (ng/mg dust), endotoxin (ng/mg dust), and $\operatorname{IgE}(\mathrm{mg} / \mathrm{mL})$ in relation to allergy

\begin{tabular}{|c|c|c|c|c|c|c|c|}
\hline \multirow[t]{2}{*}{ Allergy } & \multirow[t]{2}{*}{$n$} & \multicolumn{2}{|c|}{$\beta$-Glucan } & \multicolumn{2}{|c|}{ Endotoxin } & \multicolumn{2}{|c|}{$n \operatorname{IgE}$} \\
\hline & & $n$ & Mean (SE) & $n$ & Mean (SE) & $n$ & Mean (SE) \\
\hline No & 21 & 21 & $31.0(4.9)$ & 10 & $8.8(2.5)$ & 18 & $215(86)$ \\
\hline Yes & 73 & 51 & $31.5(3.9)$ & 24 & $3.6(0.7)^{*}$ & 50 & 209 (43) \\
\hline
\end{tabular}

their homes was analyzed, there was a lower proportion of children with allergy in this group ( 3 out of 8 as compared to 21 out of 26 in the lower exposure group. $P=0.031$ ). There was no difference in levels of IgE.

The material was finally analyzed with regard to smoking habits of the parents. In homes with smoking parents there were slightly higher values of endotoxin and $\beta$-glucan (NS). Among control children, those with rhinitis, and those with otitis, $35 \%, 24.2 \%$, and $33 \%$ of the parents were smokers, respectively. Among nonatopic children $20 \%$ of the parents were smokers as compared to $29 \%$ among the atopics. Among children with reported allergy, $20 \%$ of the parents were smokers as compared to $47 \%$ among those with no allergy $(P=0.085)$.

\section{Discussion}

The major results from the study regarding the MCWAs studied were a lower proportion of children with allergy in homes with high levels of endotoxin, a higher risk of otitis in homes with a low level of endotoxin, and a higher proportion of children with high levels of IgE and atopy in 
homes with high levels of $\beta$-glucan. The higher level of IgE among children with rhinitis was expected, as well as the higher level of IgE among atopic subjects.

The study has some shortcomings. Determinations of exposure were made using floor dust, which is different from the airborne dust that is inhaled. A number of previous studies have, however, used floor dust and found relationships with various endotoxin-induced diseases. The analysis of endotoxin and $\beta$-glucan was made using the Limulus assay, which, although very sensitive, is difficult to handle. This is illustrated by the large variations obtained when the same sample was tested in different laboratories [14]. Due to technical reasons endotoxin levels were not determined in all homes, which makes the data basis for this variable small. On the other hand, the lower levels of endotoxin in the homes of children with allergy and otitis are consistent with results from previous studies. The shortcomings in the exposure determination probably mean that the relation between exposure and different effects would have been stronger if more precise exposure methods had been used.

It has previously been reported that the population attributable fraction of atopy varied from 0 to $71 \%$ among 54,178 children in 22 countries [15]. The proportion was higher in affluent countries, which agrees with the incidence reported here $(74 \%)$ and reflects the high standard of living in Singapore.

The lower levels of endotoxin in the homes of children with allergy support the concept of endotoxin as a protective agent, elaborated in many previous studies $[3,7,8$, $16,17]$. The results also suggest that a low level of endotoxin is a risk factor for otitis, which was not characterized by increased levels of IgE. The underlying mechanism for the protective effect of endotoxin is probably a Th1-driven inflammatory response, induced by the effect of endotoxin on macrophages and induced by the TLR-4 receptor in the innate immune system [18].

Exposure to $\beta$-glucan was related to a higher level of $\mathrm{IgE}$ and a tendency to an increased risk of atopy. This agrees with previous findings where an increased prevalence of atopy was reported among children in schools where airborne moulds were found, compared to control schools with no mould damage $[19,20]$. Among preschool children, a higher odds ratio for skin prick test reactivity was related to dampness and visible mould in the home [21]. Furthermore, an association was found between Aspergillus spores and atopy in school children [22]. Among children at risk for allergy, exposure to Aspergillus at home was related to a lower content of Th1 cytokines, such as interferon $\gamma$ (IFN $\gamma$ ), tumor necrosis factor $\alpha$ (TNF $\alpha$ ), and interleukin 2 secreted from T cells [23]. These effects reflect the immunosupressive effect of non-soluble $\beta$-glucan in small doses $[24,25]$.
In conclusion, the results from the study demonstrate the importance of exposure to endotoxin and the mould cell wall agent $\beta$-glucan for the risk for rhinitis, otitis, allergy, and atopy among children.

The results suggest that both endotoxin and $\beta$-glucan/ mould exposure need to be considered in risk evaluations of indoor environments.

Acknowledgments The study was supported by a research grant from the National Medical Research Centre Start-Up Grants.

Conflict of interest statement None of the authors have any disclosures to make and none have financial or other relationships with suppliers of equipment or utensils used in the study.

\section{References}

1. Strachan D. Family size, infection and atopy-the first decade of the "hygiene hypothesis". Thorax. 2000;55:S2-10.

2. Thorne PS, Kulhankova K, Yin M, Cohn R, Arbes SJ Jr, Zeldin DC. Endotoxin exposure as a risk factor for asthma: the national survey of endotoxin in US housing. Am J Respir Crit Care Med. 2005;172:1371-7.

3. Gehring U, Strikwold M, Schram-Bijkerk D, Weinmayr G, Genuneit J, Nagel G, et al. Asthma and allergic symptoms in relation to house dust endotoxin: phase two of the international study on asthma and allergies in childhood (ISAAC II). Clin Exp Allergy. 2008;38:1911-20.

4. Smit LA, Heederik D, Doekes G, Blom C, van Zweden I, Wouters IM. Exposure-response analysis of allergy and respiratory symptoms in endotoxin-exposed adults. Eur J Respir Dis. 2008;31:1241-8.

5. Gillespie J, Wikcens K, Siebers R, Howden-Chapman P, Town I, Epton M, et al. Endotoxin exposure, wheezing, and rash in infancy in a New Zealand birth cohort. J Allergy Clin Immunol. 2006;118:1265-70.

6. Perzanowski MS, Miller RL, Thorne PS, Barr RG, Divjan A, Sheares BJ, et al. Endotoxin in inner-city homes: associations with wheeze and eczema in early childhood. J Allergy Clin Immunol. 2006;117:1082-9.

7. Braun-Fahrlander C, Riedler J, Herz U, et al. Environmental exposure to endotoxin and its relation to asthma in school-age children. N Engl J Med. 2002;347:869-77.

8. Gehring U, Bischof W, Fahlbusch B, Wichmann HE, Heinrich J. House dust endotoxin and allergic sensitisation in children. Am J Respir Crit Care Med. 2003;166:939-44.

9. Wan G-H, Li C-S, Guo S-P, Rylander R, Lin R-H. An airborne mold-derived product, $\beta$-1,3-glucan, potentiates airway allergic responses. Eur J Immunol. 1999;29:2491-7.

10. Fogelmark B, Sjöstrand M, Rylander R. Pulmonary inflammation induced by repeated inhalations of $\beta$-1,3-glucan and endotoxin. Int J Exp Pathol. 1994;75:85-90.

11. Biagini JM, LeMasters GK, Ryan PH, Levin L, Reponen T, Bernstein DI, et al. Environmental risk factors of rhinitis in early infancy. Pediatr Allergy Immunol. 2006;17:278-84.

12. Stark PC, Celedón JC, Chew GL, Ryan LM, Burge HA, Muilenberg ML, et al. Fungal levels in the home and allergic rhinitis by 5 years of age. Environ Health Perspect. 2005;113: 1405-9.

13. Pettigrew MM, Gent JF, Triche EW, Belanger KD, Bracken MB, Leaderer BP. Association of early-onset otitis media in infants 
and exposure to household mold. Paediatr Perinat Epidemiol. 2004; 18:441-7.

14. Chun DTW, Chew V, Bartlett K, Gordon T, Jacobs RR, Larsson $\mathrm{BM}$, et al. Second Inter-laboratory study comparing endotoxin assay results from cotton dust. Ann Agric Environ Med. 2002;9:49-53.

15. Weinmayr G, Forastiere F, Weiland SK, Rzehak P, Abramidaze $\mathrm{T}$, Annesi-Maesano I, et al. International variation in prevalence of rhinitis and its relationship with sensitisation to perennial and seasonal allergens. Eur Respir J. 2008;32:1250-61.

16. von Mutius E, Braun-Fahrländer C, Schierl R, Riedler J, Ehlermann S, Maisch S, et al. Exposure to endotoxin or other bacterial components might protect against the development of atopy. Clin Exp Allergy. 2000;30:1230-4.

17. Song BJ, Liu AH. Metropolitan endotoxin exposure, allergy and asthma. Curr Opin Allergy Clin Immunol. 2003;3:331-5.

18. Simpson A, Martinez FD. The role of lipopolysaccharide in the development of atopy in humans. Clin Exp Allergy. 2009; 40:209-23.

19. Rylander R, Norrhall M, Engdahl U, Tunsäter A, Holt PG. Airways inflammation, atopy, and $(1 \rightarrow 3)-\beta$-D-glucan exposures in two schools. Am J Respir Crit Care Med. 1998;158:1685-7.
20. Savilahti R, Uitti J, Roto P, Laippala P, Husman T. Increased prevalence of atopy among children exposed to mould in a school building. Allergy. 2001;56:175-9.

21. Schäfer T, Krämer U, Dockery D, Vieluf D, Behrendt H, Ring J. What makes a child allergic? Analysis of risk factors for allergic sensitisation in preschool children from East and West Germany. Allergy Asthma Proc. 1999;20:23-7.

22. Garrett MH, Rayment PR, Hooper MA, Abramson MJ, Hooper $\mathrm{BM}$. Indoor air fungal spores, house dampness and associations with environmental factors and respiratory health in children. Clin Exp Allergy. 1998;28:459-67.

23. Müller A, Lehmann I, Seiffart A, Diez U, Wetzig H, Borte M, et al. Increased incidence of allergic sensitisation and respiratory diseases due to mould exposure: results of the Leipzig Allergy Risk children Study (LARS). Int $\mathrm{J}$ Hyg Environ Health. 2002;204:363-5.

24. Rylander R, Holt PG. ( $1 \rightarrow 3)-\beta$-D-glucan and endotoxin modulate immune response to inhaled allergen. Mediators Inflamm. 1998;7:105-110.

25. Rylander R. Effects of inhaled 1, 3- $\beta$-glucan: proposal for a model. Mediators Inflamm. 2007;5-7 (article 79648). 